\title{
Hydrogen Abstraction from Fluorinated Ethyl Methyl Ether Systems by $\mathrm{OH}$ Radicals
}

\author{
Curtis W. White and Jaime M. Martell \\ Department of Chemistry, Cape Breton University, Sydney, NS, Canada B1P 6L2 \\ Correspondence should be addressed to Jaime M. Martell; jaime_martell@cbu.ca \\ Received 30 July 2015; Revised 3 November 2015; Accepted 5 November 2015 \\ Academic Editor: Michael D. Sevilla
}

Copyright ( 2016 C. W. White and J. M. Martell. This is an open access article distributed under the Creative Commons Attribution License, which permits unrestricted use, distribution, and reproduction in any medium, provided the original work is properly cited.

\begin{abstract}
A systematic computational investigation of hydrogen abstraction by $\mathrm{OH}$ from the full series of fluorinated ethyl methyl ethers (EME) containing at least one $\mathrm{H}$ and one $\mathrm{F}, \mathrm{C}_{2} \mathrm{H}_{n} \mathrm{X}_{5-n} \mathrm{OCH}_{m} \mathrm{X}_{3-m}(n=0-5, m=0-3$; and $n=m=0$ not allowed), including 147 reactants and 469 transition states, has been carried out, employing the MP2/6-31G(d) level of theory. Results for optimized geometries, including evidence of intramolecular hydrogen bonding in transition states, and barrier heights are presented. Trends pertaining to the number of fluorines substituted, key bond lengths, barrier heights, and key bond angles were found with good correlations and were investigated. An increase in the number of $\mathrm{F}$ increases the barrier height of the reaction. An increase in some parameters such as $\mathrm{C}-\mathrm{H}$ length of TS, relative change in $\mathrm{C}-\mathrm{H}$ from reactants to TS, $\angle \mathrm{COC}$ of reactants, $\angle \mathrm{HOH}$ in the TS, and relative change in $\angle \mathrm{HOH}$ between TS and free water bond angle also correlates with increased barrier height. An increase in other parameters like $\mathrm{C}-\mathrm{H}$ length in the reactants and hydrogen bonding can decrease the barrier height.
\end{abstract}

\section{Introduction}

Hydrofluorocarbons (HFCs) are among the leading environmentally acceptable alternatives to ozone destroying chlorofluorocarbons (CFCs). The determination of atmospheric lifetimes of HFCs is a key in assessing their environmental impact. They initially degrade in the troposphere through hydrogen atom abstraction by relatively abundant hydroxyl radicals. The literature is replete with studies on HFCs [1], their atmospheric reactions, and reactions of their degradation products [2].

Partially fluorinated ethers have been proposed as second-generation HFC replacements $[3,4]$ because of their low ozone depletion potentials and their suspected shorter atmospheric lifetimes as compared to analogous HFCs, which thus reduces their global warming potential. In a study of more than 150 fluorinated ethers, Sekiya and Misaki [3] determined that in the ethyl methyl ether (EME) series, $\mathrm{CF}_{3} \mathrm{CF}_{2} \mathrm{OCH}_{3}$ and $\mathrm{CF}_{3} \mathrm{CHFOCF}_{3}$ show promise as replacement refrigerants. Degradation in the troposphere is initiated by reaction with hydroxyl radicals $\left({ }^{\circ} \mathrm{OH}\right)$ to produce water and an ether radical. There are only a few published experimental studies on ${ }^{\circ} \mathrm{OH}$ reaction rates for this class of compounds [5-7], and most of them report absolute rates, which have the disadvantage of being susceptible to spurious ${ }^{\circ} \mathrm{OH}$ loss due to impurities or secondary products. Hsu and DeMore [8] used a relative rate technique for the reactions of ${ }^{\circ} \mathrm{OH}$ radicals with $\mathrm{CF}_{3} \mathrm{OCH}_{3}$, $\mathrm{CF}_{2} \mathrm{HOCF}_{2} \mathrm{H}$, and $\mathrm{CF}_{3} \mathrm{OCF}_{2} \mathrm{H}$. They found significantly slower reaction rates for the latter two, which translates to significantly longer atmospheric lifetimes than previously estimated [9]. They also determined $\mathrm{C}-\mathrm{H}$ bond strengths. More recent work [10] includes a study of rate constants in the range 250-430 $\mathrm{K}$ for $\mathrm{CH}_{3} \mathrm{OCF}_{2} \mathrm{CHF}_{2}, \mathrm{CHF}_{2} \mathrm{OCH}_{2} \mathrm{CF}_{2} \mathrm{CHF}_{2}$, $\mathrm{CHF}_{2} \mathrm{OCH}_{2} \mathrm{CF}_{2} \mathrm{CF}_{3}$, and $\mathrm{CF}_{3} \mathrm{CH}_{2} \mathrm{OCF}_{2} \mathrm{CHF}_{2}$. The same group carried out theoretical work on smaller ethers [11, 12], but their computations for reactions with ${ }^{\circ} \mathrm{OH}$ have been limited to halogenated formates $[13,14]$. There is also very little data on the barrier heights, reaction enthalpies, and bond dissociation energies of partially fluorinated ethers. A theoretical study by Good and Francisco [15], also on $\mathrm{CF}_{3} \mathrm{OCH}_{3}, \mathrm{CF}_{2} \mathrm{HOCF}_{2} \mathrm{H}$, and $\mathrm{CF}_{3} \mathrm{OCF}_{2} \mathrm{H}$, yielded $\mathrm{C}-\mathrm{H}$ bond dissociation energies (which supported the experimentally determined bond strengths [8]) and heats of formation. 

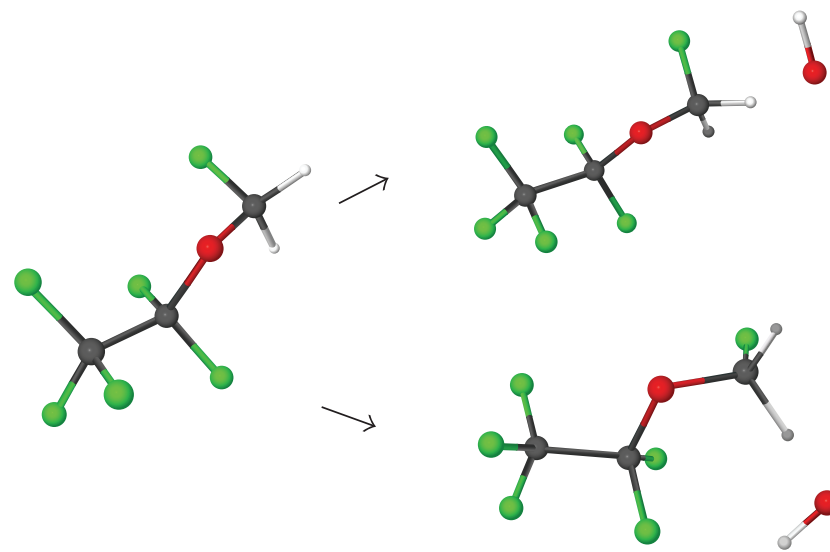
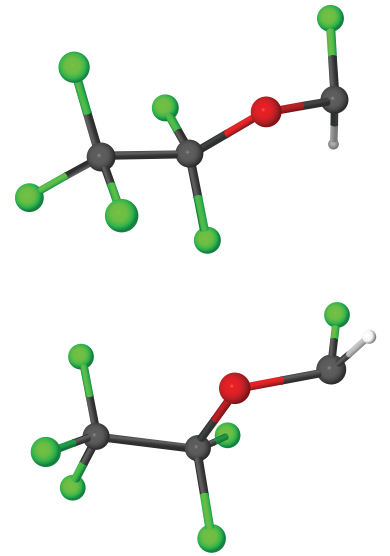

FIGURE 1: An example showing two possibilities of the hydrogen abstraction by the hydroxyl radical in the same EME.

Blowers et al. [16] performed a study on the global warming potentials of hydrofluorodimethylethers using B3LYP/6$31 G(d)$.

In our previous work on unimolecular decompositions of these ethers the B3LYP functional was used. However, ElNahas et al. [17] found that even after an extensive search the B3LYP functional could not find a stationary point for the TS of the hydrogen abstraction reaction of ${ }^{\circ} \mathrm{OH}$ with dimethyl ether. More generally, Johnson et al. [18] found that most DFT methods tend to underestimate barrier heights for $\mathrm{H}$ abstraction reactions and in some cases the barrier can completely disappear and no minima can be found. Gill et al. propose [19] that the reason for DFT's poor performance in these cases is the so-called self-interaction error that arises when one uses a local functional for exchange, and the problem can be partly fixed by improving the treatment of exchange. One method is to add some exact exchange to the density functional (this is what B3LYP and other hybrids do). However, B3LYP only uses $20 \%$ of exact exchange, whereas some modern hybrids address the barrier-height problem by using a much larger fraction of exact exchange. For example, the BMK functional uses about 50 percent [20]. While this may improve calculated barrier heights, B3LYP is still more widely employed, as it provides reasonably accurate results for a greater array of chemical problems.

A systematic investigation of hydrogen abstraction by - $\mathrm{OH}$ for the full series of fluorinated EME (containing at least one $\mathrm{H}$ and one F) $\mathrm{C}_{2} \mathrm{H}_{n} \mathrm{X}_{5-n}-\mathrm{O}-\mathrm{CH}_{m} \mathrm{X}_{3-m}(n=0-5$; $m=0-3$; and $n=m=0$ not allowed) with a maximum of seven fluorines (F) was carried out. Figure 1 illustrates a reaction of two different hydrogen abstraction pathways from the same EME.

There are different ways in which ${ }^{\circ} \mathrm{OH}$ can attack the EME. This research covered every possibility for $\mathrm{H}$ abstraction on each molecule and also every structural isomer.

\section{Calculations}

All calculations were performed using the Gaussian 03, Revision D.01 [21] program through the WebMO interface. Test cases for TS optimization were conducted with the
B3LYP, BMK, M05, M05-2X, M06, and M06-2X functionals. The full set of calculations were performed with the MP2 level of theory; all calculations used the 6-31G(d) basis set. TS were calculated using extra cycles to obtain optimization by using the keyword MAXCYCLES $=400$. For open-shell species, values of $S^{2}$ ranged from 0.751 to 0.793 , indicating minor spin contamination.

The structural parameters of the different isomers of fluorinated EME with the formula $\mathrm{C}_{2} \mathrm{H}_{n} \mathrm{X}_{5-n}-\mathrm{O}-\mathrm{CH}_{m} \mathrm{X}_{3-m}$ ( $n=0-5, m=0-3$; and $n=m=0$ not allowed) where seven is the maximum limit of substitution were studied. Barrier heights were determined by taking the energy difference between TS and sum of reactants $(\mathrm{EME}+\mathrm{OH})$, where the energy of each species included the electronic and zero-point energies. The structures of the TS can be seen in Appendix A of the Supplementary Material available online at http://dx.doi.org/10.1155/2016/3740278.

\section{Nomenclature}

A simple naming system was devised for this study in order to avoid confusion between reactants and TS. The first character of the name indicates the number of F. For example, difluorinated isomers start with $2 \mathrm{~F}$.

The second part of the name distinguishes between isomers and is denoted by lowercase letters, assigned arbitrarily. For example, a molecule with two $\mathrm{F}$ has fifteen different isomers, which are labelled $2 \mathrm{~F}_{-}$a to $2 \mathrm{~F}_{-}$. If there are more than 26 isomers, a second letter was added beginning with $\# \mathrm{~F} \_$aa to $\# \mathrm{~F} \_$az. An example of two isomers is given in Figure 2.

For the TS a third part of the name was introduced to distinguish between the different TS. Thus the final part of the name is "TS" followed by a number to designate which hydrogen is being abstracted by the ${ }^{\circ} \mathrm{OH}$ radical; again, it is assigned arbitrarily (a detailed list can be found in Appendix A). For example a molecule with two F in the "b" conformation has five nonequivalent hydrogens; thus we will have five TS called 2F_b_TS1, 2F_b_TS2, 2F_b_TS3, 2F_b_TS4, and 2F_b_TS5, as seen in Figure 3. 

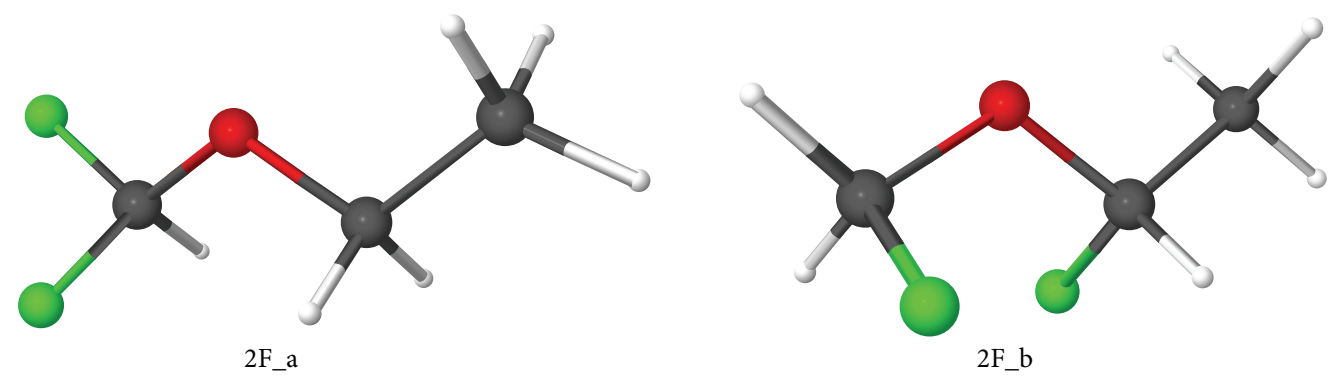

FIgURE 2: Two examples of EME reactants with two F substitutions in different positions.
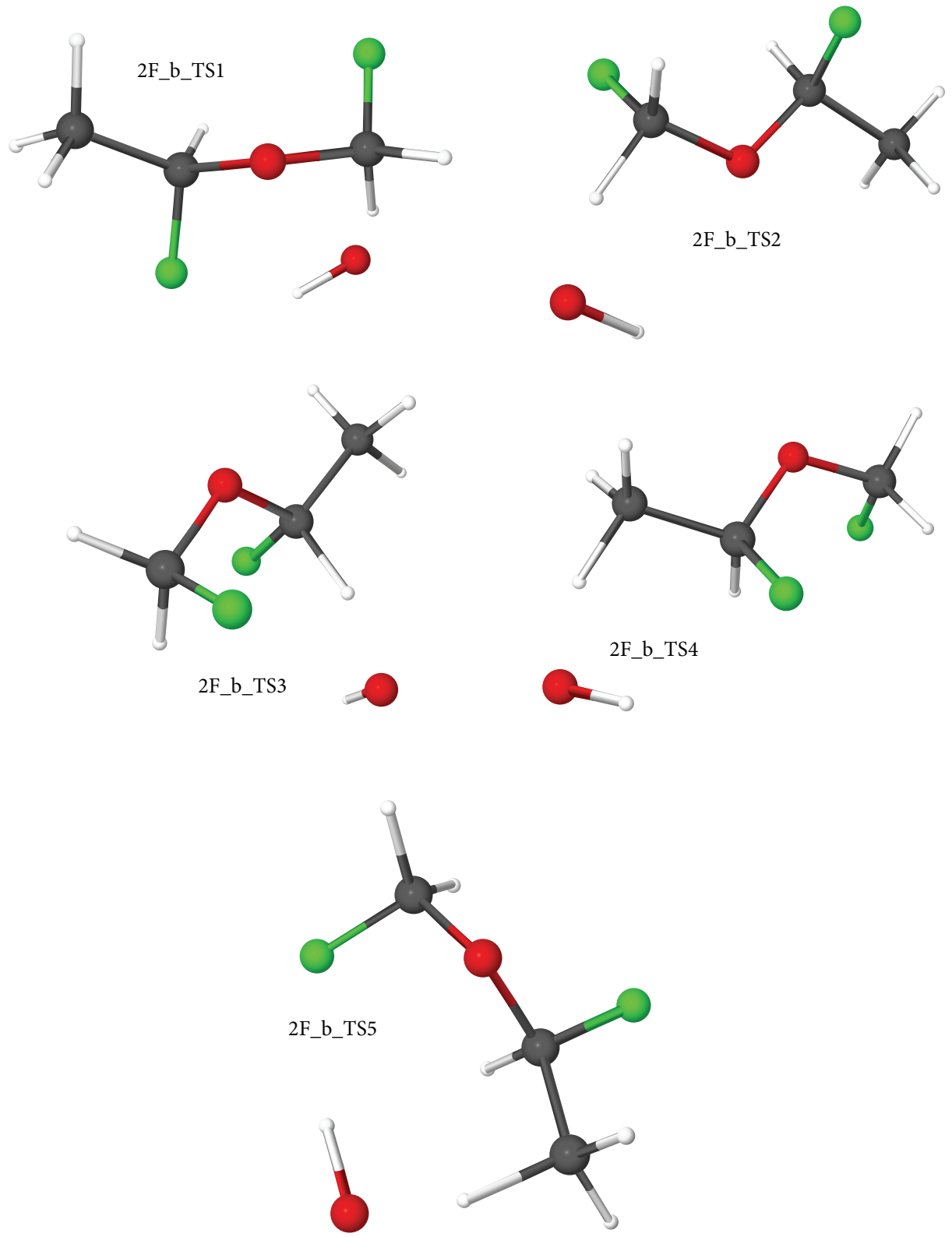

Figure 3: TS of 2F_b. 
TABLE 1: Average key bond lengths $(\AA ̊)$.

\begin{tabular}{lccc}
\hline Number of F & $\begin{array}{c}\text { Average C-H } \\
\text { (reactant) }\end{array}$ & $\begin{array}{c}\text { Average C-H } \\
\text { (TS) }\end{array}$ & $\begin{array}{c}\text { Average } \mathrm{H}-\mathrm{O}_{\text {rad }} \\
\text { (TS) }\end{array}$ \\
\hline 1 & 1.095 & 1.214 & 1.309 \\
2 & 1.094 & 1.221 & 1.289 \\
3 & 1.093 & 1.226 & 1.275 \\
4 & 1.050 & 1.240 & 1.266 \\
5 & 1.092 & 1.236 & 1.255 \\
6 & 1.091 & 1.240 & 1.243 \\
\hline
\end{tabular}

\section{Results and Discussion}

The choice of theoretical method was determined by the success in locating TS structures. No success was obtained using B3LYP, BMK, M05, M05-2X, M06, and M06-2X. This forced a choice of the more costly second-order MollerPlesset perturbation (MP2) with the routine 6-31G(d) basis set. The MP2 method does give accurate results, but it costs more in terms of both resources and time. Previous work with this method showed excellent agreement with experiment for geometries (within $0.01 \AA$ for lengths and less than $2^{\circ}$ for angles) for the full series of fluorinated ethanes, $\mathrm{C}_{2} \mathrm{H}_{n} \mathrm{~F}_{6-n}$ $(n=0-6)$ [22], and good agreement for barrier heights for their reactions with $\mathrm{OH}[23,24]$. MP2 is generally considered to give accurate geometries [25] and is typically used to obtain geometries for the various $\mathrm{G} n$ methods, including G2 [26], G3 [27], and G3(MP2) [28]. For barrier heights, it tends to systematically underestimate values, but in many cases in the range of $3-5 \mathrm{kcal} \mathrm{mol}^{-1}[25,29]$.

4.1. Geometries. In total, the geometries of 147 reactants and 469 TS were determined computationally using the MP2 method and 6-31G(d) basis set. For reactants with equivalent hydrogens, only one of the equivalent hydrogens was abstracted, reducing the amount of TS and avoiding duplication. The key interatomic distances (in Ångstroms), the $\mathrm{C}-\mathrm{H}$ bond being broken and $\mathrm{O}-\mathrm{H}$ bond being formed, are tabulated in Appendices B and C. The reactant's average C$\mathrm{H}$ decreases as the number of $\mathrm{F}$ increases and the TS average $\mathrm{C}-\mathrm{H}$ increases as the number of $\mathrm{F}$ increases, each having an outlier for molecules with four $\mathrm{F}$. The average $\mathrm{H}-\mathrm{O}_{\mathrm{rad}}$ in the TS decreases as the number of $F$ increases. This can be seen in Table 1.

Output from the optimization of the reactants and TS was also used to measure key bond angles in the abstraction reaction and results can be seen in Appendix D. All bond angles are increased as the number of $\mathrm{F}$ is increased. This can be seen in Table 2.

4.2. Barrier Heights. Barrier heights were calculated using the electronic and zero point energies of the reactants and TS calculated by Gaussian. The barrier heights are all reported in $\mathrm{kJ} \mathrm{mol}^{-1}$ and are tabulated in Appendix E.

For the first of these trends, note that these are trends of the entire system, using average values. These trends will not deal with hydrogen bonding, conformations, and other
TABLE 2: Average key bond angles $\left({ }^{\circ}\right)$.

\begin{tabular}{lcccc}
\hline Number of F & $\begin{array}{c}\mathrm{COC} \\
\text { (reactants) }\end{array}$ & COC (TS) & $\begin{array}{c}\mathrm{CHO}_{\text {rad }} \\
\text { (TS) }\end{array}$ & $\begin{array}{c}\mathrm{HOH}_{\text {rad }} \\
\text { (TS) }\end{array}$ \\
\hline 1 & 112.1 & 112.5 & 161.6 & 97.4 \\
2 & 112.8 & 113.5 & 160.6 & 97.3 \\
3 & 113.6 & 114.2 & 161.2 & 97.9 \\
4 & 114.4 & 114.9 & 161.4 & 98.5 \\
5 & 115.1 & 115.6 & 162.1 & 99.1 \\
6 & 115.7 & 116.5 & 164.3 & 99.6 \\
\hline
\end{tabular}

TABLE 3: Average barrier heights for EME with the same number of F.

\begin{tabular}{lcc}
\hline Number of $F$ & Number of isomers & $\begin{array}{c}\text { Average barrier heights } \\
(\mathrm{kJ} / \mathrm{mol})\end{array}$ \\
\hline 1 & 5 & 32.8 \\
2 & 15 & 32.9 \\
3 & 28 & 36.2 \\
4 & 36 & 39.6 \\
5 & 28 & 42.4 \\
6 & 15 & 46.4 \\
\hline
\end{tabular}

interactions but are rather more of a qualitative analysis. The first is the trend of the number of F on an EME and their corresponding barrier height to abstract a hydrogen using an - $\mathrm{OH}$ radical. As more $\mathrm{F}$ are placed on the molecule the higher the barrier height. This trend has a good correlation with a calculated $R^{2}$ value of 0.9720 . These results can be seen in Figure 4 and Table 3.

4.3. Barrier Height versus Bond Lengths Trends. The trend noted in Section 4.2 can be explained by a number of factors. First, the bond length of the $\mathrm{C}-\mathrm{H}$ gets smaller when more $\mathrm{F}$ are added to the EME. With $\mathrm{F}$ being the most electronegative atom in the periodic table, this trend is not surprising. F pulls electron density towards itself, by an inductive effect, with the electron density in the $\mathrm{C}-\mathrm{H}$ polarized towards carbon. This makes the $\mathrm{C}-\mathrm{H}$ stronger. If the $\mathrm{C}-\mathrm{H}$ is stronger, then it will take more energy for the ${ }^{\circ} \mathrm{OH}$ to abstract the $\mathrm{H}$, thus making the barrier height larger. Thus, it is expected that the more the $\mathrm{F}$ in the molecule, the tighter the $\mathrm{H}$ bonds and the higher the barrier height. There is one outlier (red square in Figure 5) which is EME with four F. This is thought to be a result of extensive hydrogen bonding between the hydrogens and the F and oxygen. This trend can be seen in Figures 5-7. Figures 5 and 7 have good second-order polynomial correlations. Figure 5 however has an outlier which is the group of molecules with $4 \mathrm{~F}$ due to hydrogen bonding interactions. This will be discussed later.

The second factor that can explain the trend seen in Figure 9 is that the smaller the change the $\mathrm{C}-\mathrm{H}$ bond undergoes from its reactant bond length to its TS bond length, the smaller the barrier height. This is consistent with the principal of least motion. The more the bond length must change, the more the energy must be put into the reactant to achieve 


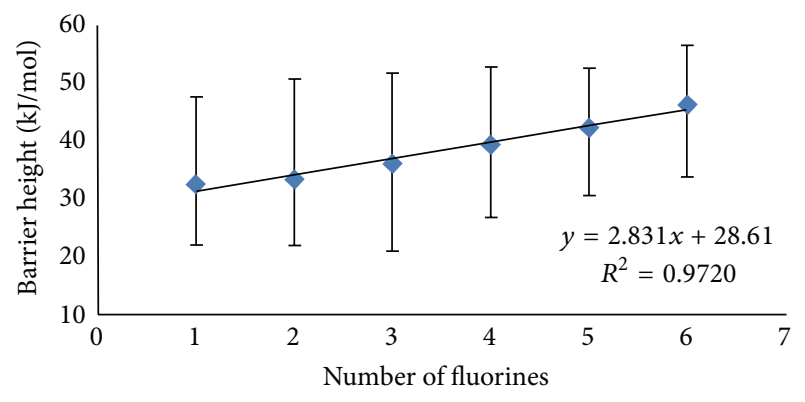

FIGURE 4: Average barrier height versus the number of F substituted on an EME.

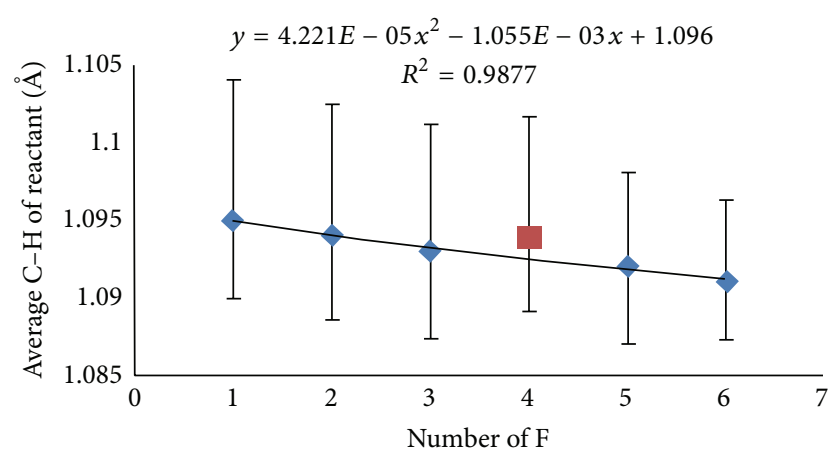

Figure 5: Average $\mathrm{C}-\mathrm{H}$ of the TS versus the number of $\mathrm{F}$.

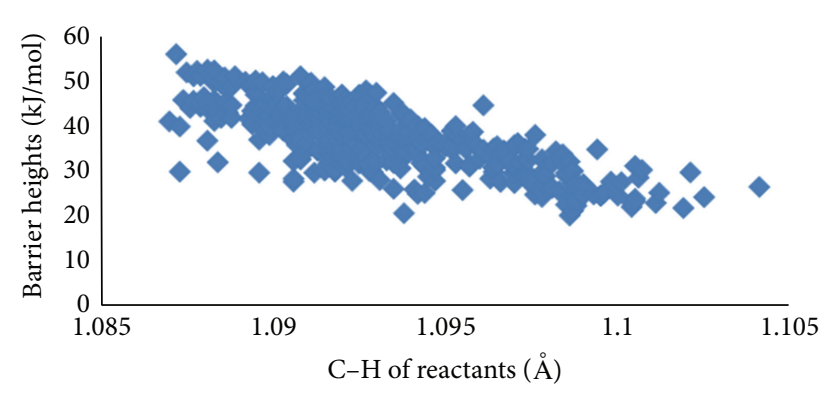

Figure 6: Barrier heights versus $\mathrm{C}-\mathrm{H}$ of TS.

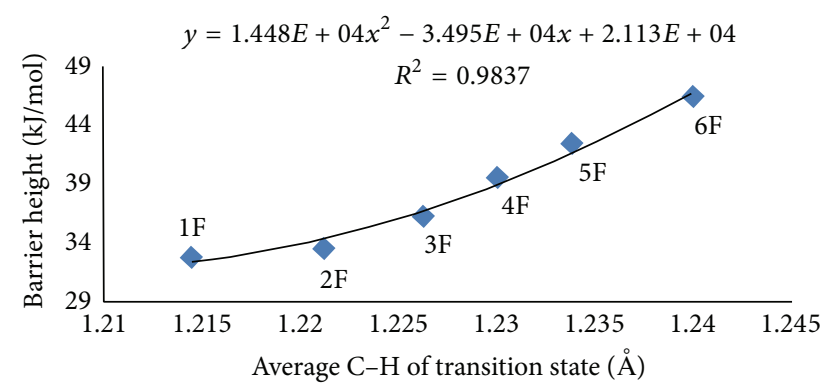

FIGURE 7: Average barrier heights versus average C-H of TS.

the TS, so the barrier height goes up. As the number of F increases, the bond length of the hydrogen being abstracted in the TS also increases, making the percent that the bond length must change from the reactant to the TS increase. These trends can be seen in Figures 8-10, where average refers to the average values for molecules with the same number

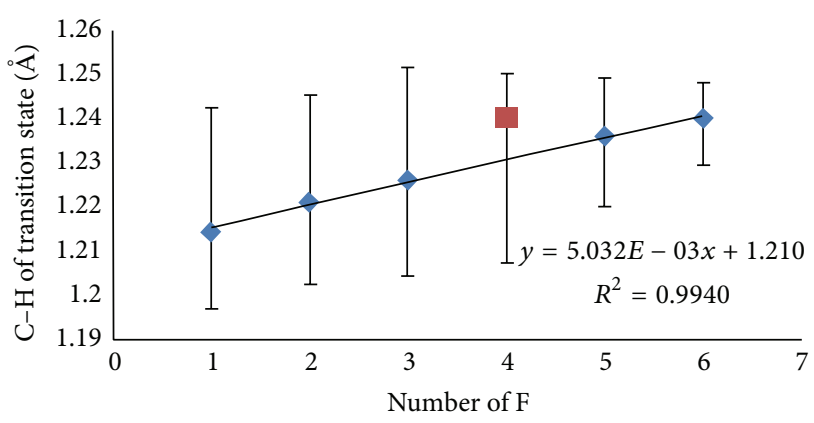

FIgure 8: Average TS C-H versus the number of F.

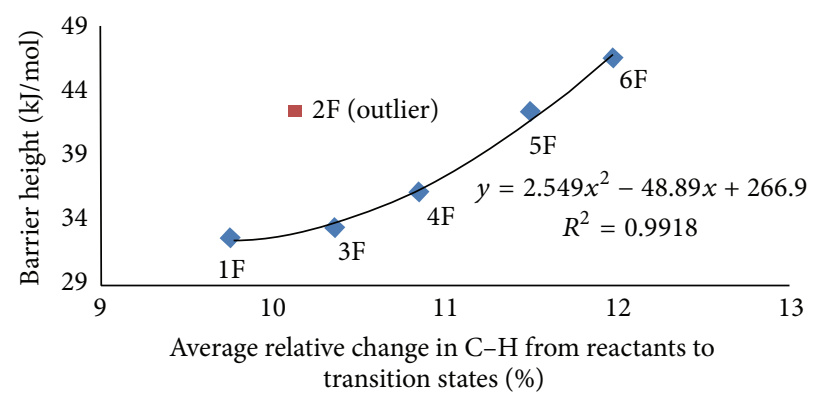

FIgURE 9: Average barrier height versus average relative change in $\mathrm{C}-\mathrm{H}$ from reactants to TS (\%).

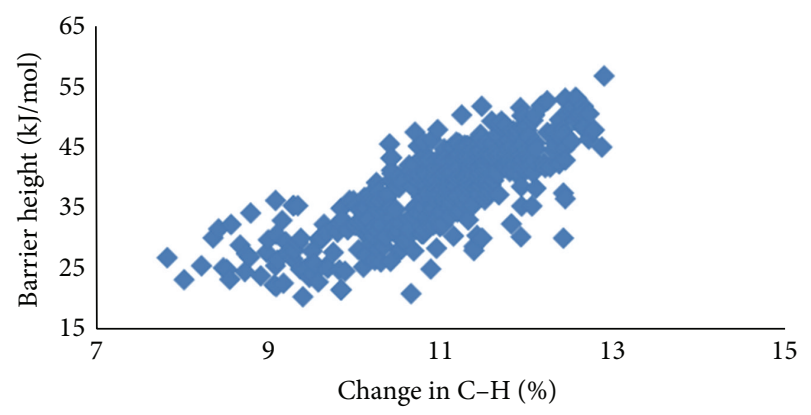

Figure 10: Barrier height versus relative change in $\mathrm{C}-\mathrm{H}$ from reactants to TS (\%).

of F. Figure 8 shows an excellent linear correlation with one outlier at molecules with $4 \mathrm{~F}$ while Figure 9 shows an excellent second-order polynomial correlation with one outlier.

Figures 5 and 8 show opposite trends. In Figure 5, it can be seen that the more $\mathrm{F}$ on the EME the smaller the $\mathrm{C}-\mathrm{H}$ length of the hydrogen being abstracted in the reactant, yet in Figure 8 the more the F on the EME the longer the bond length in the TS. This is complementary to $\mathrm{C}-\mathrm{H}$ length trends found by Martell and Boyd in a similar study on fluorinated ethanes [24].

Since the trends are opposite, as the number of $\mathrm{F}$ goes up, the percent that the bond length must change from the reactant to the TS also increases. If the percent change in the bond length goes up, then there must be more energy put into the reactant to get over the reaction barrier, increasing the barrier height (it is a later TS). Figure 10, a plot of the average relative change in the $\mathrm{C}-\mathrm{H}$ length between reactant and TS 
TABLE 4: Hydrogen bonding to oxygen and $\mathrm{F}$ and average barrier heights.

\begin{tabular}{|c|c|c|c|c|c|c|}
\hline Number of $\mathrm{F}$ & $\begin{array}{c}\text { Percent of } \\
\text { occurrences of } \mathrm{H} \\
\text { bonds to } \mathrm{F}\end{array}$ & $\begin{array}{c}\text { Percent of } \\
\text { occurrences of } \mathrm{H} \\
\text { bonds to } \mathrm{O}_{\text {ether }}\end{array}$ & $\begin{array}{c}\text { Average } \\
\text { barrier height }\end{array}$ & $\begin{array}{c}\text { Average barrier } \\
\text { height with no } \\
\text { H bonds }\end{array}$ & $\begin{array}{l}\text { Average barrier height } \\
\text { with } \mathrm{H} \text { bonds to } \mathrm{F}\end{array}$ & $\begin{array}{c}\text { Average barrier } \\
\text { height with } \mathrm{H} \\
\text { bonds to } \mathrm{O}_{\text {ether }}\end{array}$ \\
\hline 1 & 23.8 & 42.9 & 32.8 & 38.1 & 23.5 & 32.7 \\
\hline 2 & 69.3 & 30.7 & 33.5 & 36.1 & 32.6 & 35.4 \\
\hline 3 & 72.4 & 31.5 & 36.2 & 42.1 & 35.1 & 38.7 \\
\hline 4 & 75.0 & 31.1 & 39.6 & $\mathrm{n} / \mathrm{a}$ & 38.9 & 41.1 \\
\hline 5 & 91.8 & 30.1 & 42.5 & $\mathrm{n} / \mathrm{a}$ & 42.0 & 44.6 \\
\hline 6 & 92.6 & 29.6 & 46.5 & $\mathrm{n} / \mathrm{a}$ & 46.1 & 47.5 \\
\hline
\end{tabular}

versus the average barrier height, shows this with an excellent second-order polynomial correlation with one outlier.

Hydrogen bonding also plays a key role in the barrier heights and the trends they follow. As a first approximation, hydrogen bonding for this study was determined to be any interatomic distance between $\mathrm{F}$ and $\mathrm{O}$ or $\mathrm{H}$ and $\mathrm{O}$ less than $2.5 \AA$. Two trends that are obvious right away are how many hydrogen bonds to $\mathrm{F}$ and how many hydrogen bonds to oxygen there are with respect to the number of $\mathrm{F}$ in the molecule. In molecules with low numbers of $\mathrm{F}$, hydrogen bonding to oxygen is dominant. For example, for molecules with one $\mathrm{F}$, the position of it can be at the ends, unavailable to hydrogen bond with the incoming ${ }^{\bullet} \mathrm{OH}$ radical. In molecules with high numbers of $\mathrm{F}$, hydrogen bonding with $\mathrm{F}$ is dominant. For example, for molecules with $6 \mathrm{~F}$, there is an $\mathrm{F}$ in almost every position and the ${ }^{\circ} \mathrm{OH}$ radical can interact with any of them. These trends can be seen in Table 4 .

It can also be seen that as soon as the second $\mathrm{F}$ is placed on the EME, hydrogen bonds to $\mathrm{F}$ become dominant over hydrogen bonds to oxygen. This is because $\mathrm{F}$ is a more electronegative atom and if the ${ }^{\circ} \mathrm{OH}$ radical abstracting the hydrogen comes close enough it will react more strongly with the $\mathrm{F}$ than with the oxygen. This is not to say that there are no occurrences where there are hydrogen bonds to oxygen and $\mathrm{F}$ at the same time.

When the hydrogen being abstracted comes from the center of the molecule, this also accounts for the smaller barrier heights in the TS with the same reactant molecule. This shows that the hydrogens bonded to the middle carbon are the easiest to be abstracted and this may be due to the hydrogen bonding to oxygen. If we look at plots of hydrogen bonding to oxygen and $F$ versus the number of $F$ we see that as the percent of hydrogen bonding to oxygen increases then the barrier height decreases and as the percent hydrogen bonding to $\mathrm{F}$ increases barrier height increases. This can also be seen in Table 4.

Hydrogen bonding to $\mathrm{F}$ gives the lowest barrier heights and are consistently lower than the average barrier height. Hydrogen bonding to oxygen gives lower barrier heights than the average for EME with two F or less but gives higher barrier heights than average for EME with more than two F. If the EME has no hydrogen bonding, EME that has three or less $\mathrm{F}$, the barrier heights are higher than the average. From this it can be seen that hydrogen bonding reduces the barrier height.

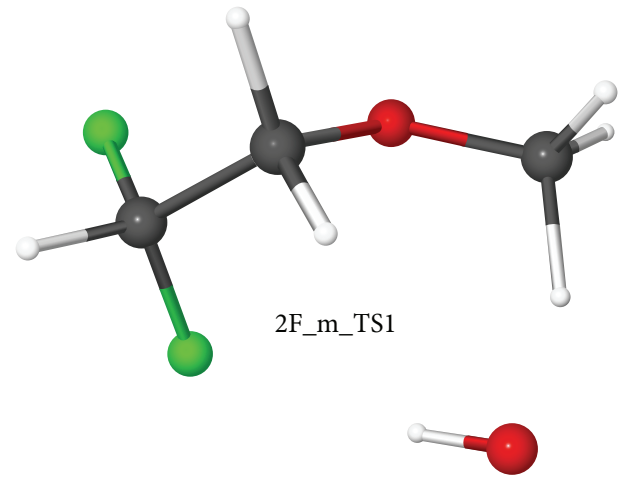

FIGURE 11: TS structure with cyclic structure.

There are some molecules in which the structure is twisted to form almost a cyclic structure in the TS. This happens particularly in the groups with 2 or $3 \mathrm{~F}$, with the hydrogen being abstracted being on one end of the molecule and an $\mathrm{F}$ being on the other end. It appears that the ${ }^{\circ} \mathrm{OH}$ radical oxygen binds to the hydrogen being abstracted from the ether and the hydrogen of the ${ }^{\circ} \mathrm{OH}$ radical binds with the $\mathrm{F}$ on the other end of the molecule. Isomers that have this happening have some of the smaller barrier heights in comparison with other TS in the same group. Some examples of this are 2F_c_TS5, 2F_m_TS1, and 3F_aa_TS1 and the structure of 2F_m_TS1 can be seen in Figure 11.

When the $\mathrm{O}-\mathrm{H}$ length of the TS with $\mathrm{O}$ being oxygen from the radical and $\mathrm{H}$ being the hydrogen being abstracted is looked at there is a very clear trend. As more $\mathrm{F}$ are added the $\mathrm{O}-\mathrm{H}$ length is decreased. $\mathrm{F}$ is the most electronegative atom; therefore when there is more than one interacting with the hydroxyl radical, each would pull the radical a little closer. The results can be seen in Figure 12 which has an excellent second-order polynomial correlation.

4.4. Barrier Height versus Bond Angle Trends. The next part of the study was to look at key structural features such as the $\angle \mathrm{COC}$ of the ether in the reactant and TS, the $\angle \mathrm{CHO}$, and the $\angle \mathrm{HOH}$ in the TS. These features will be looked at in relation to barrier heights and number of $\mathrm{F}$ on the ether to look for correlations between the two.

In Figure 13, there is a clear linear correlation in that the average $\angle C O C$ increases with the number of $F$, both in the 


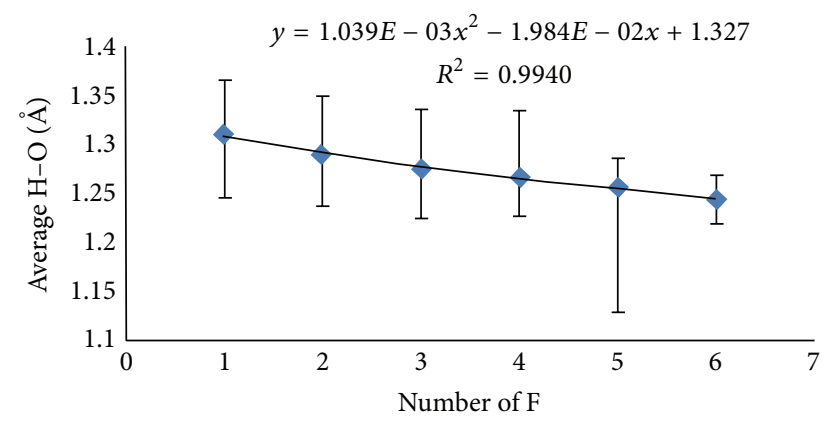

FIgURE 12: Average $\mathrm{H}-\mathrm{O}_{\text {radical }}$ versus the number of F.

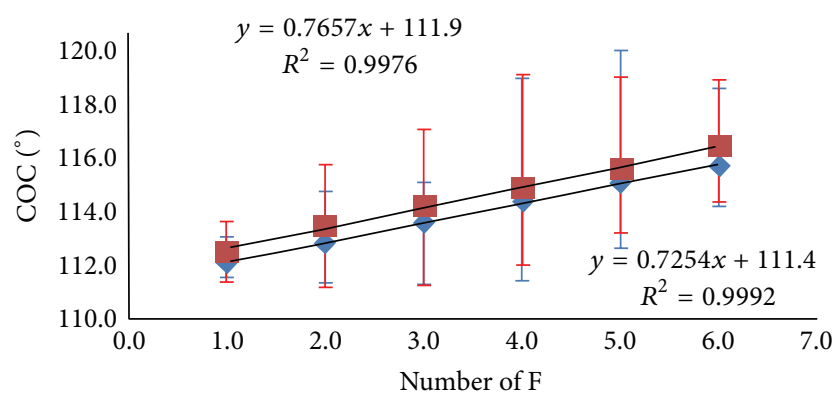

FIGURE 13: Average $\angle C O C$ of reactant versus the number of F (red) and average $\angle \mathrm{COC}$ of TS versus the number of $\mathrm{F}$ (blue).

reactants (red symbols), which is almost perfectly linear with an $R^{2}=0.999$; and in the TS (blue symbols), again it is nearly perfectly linear with $R^{2}=0.9976$. Because these correlations are so strong we can assume that the number of $\mathrm{F}$ on the molecule has a very strong role in determining the $\angle \mathrm{COC}$ in both the reactant and TS. The $\angle \mathrm{COC}$ is determined by how far away electron density is around the oxygen. F pull density away from the oxygen, so the angle opens up.

When the $\angle C O C$ was plotted against the barrier heights (see Figure 14), there were some odd trends occurring. There are vertical groupings of the barrier heights with respect to the $\angle C O C$ in the reactants. There are six groupings, so it almost looked like each group of ethers with a specific number of $\mathrm{F}$ gave only ranges of bond angles that were close to the average.

When being looked at closer, however, it could be seen that the groupings in the table were just coincident. Each group of ethers with the same $\mathrm{F}$ gave a range of $\angle \mathrm{COC}$. The lower limit in molecules with one to four $\mathrm{F}$ was almost the same with a deviation of only about $0.1^{\circ}$. There is a lot of overlap in the ranges with the upper and lower limits being different. The molecules with five $\mathrm{F}$ have a bond angle increased about 1 degree from groups with one to four and molecules with six F having a bond angle increased about 2 degrees from molecules with five $\mathrm{F}$. The upper range increases as the number of $\mathrm{F}$ is increased. Also there is a large increase in the magnitude of the range in EME with four and five F. This is seen in Table 5 .
TABLE 5: Number of F and their $\angle$ COC ranges of reactants.

\begin{tabular}{lcc}
\hline Number of F & COC range of reactants $\left(^{\circ}\right)$ & Range magnitude \\
\hline 1 & $111.5-113.0$ & 1.5 \\
2 & $111.4-114.8$ & 3.4 \\
3 & $111.3-115.1$ & 3.8 \\
4 & $111.4-118.9$ & 7.5 \\
5 & $112.7-120.0$ & 7.3 \\
6 & $114.2-118.6$ & 1.4 \\
\hline
\end{tabular}

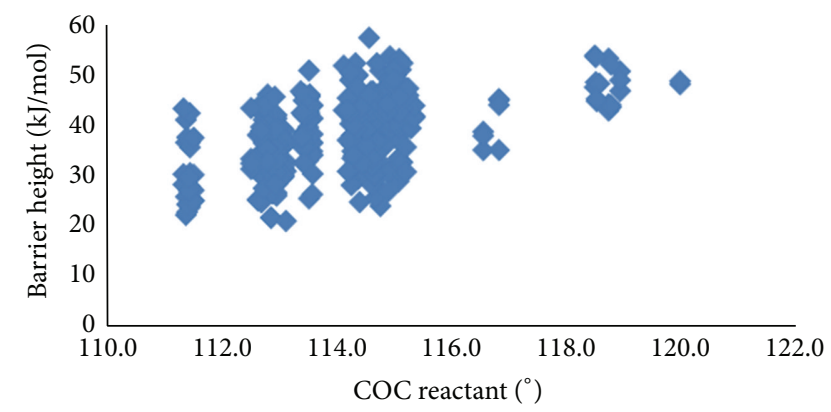

FIGURE 14: Barrier height versus $\angle \mathrm{COC}$ of reactant.

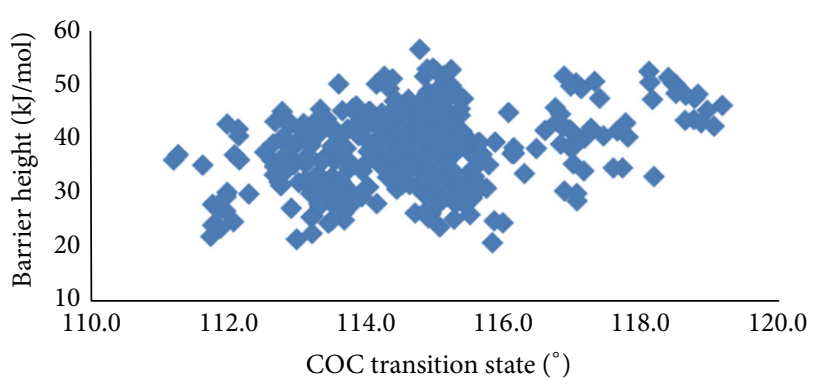

FIgURE 15: Barrier heights versus COC of the TS.

The same sort of thing happened in the TS except without the vertical groupings when plotted against the barrier heights. The plot in Figure 15 is highly scattered.

The ranges are a little different from the reactants though in that the upper limits are slightly increased. The lower limits stay relatively the same and are shown in Table 6.

Another key structural feature of this reaction appears in the TS. When the $\angle \mathrm{CHO}$ (where carbon and hydrogen are on the ether and oxygen comes from the radical) is plotted against the number of $\mathrm{F}$, we can see a linear relationship that as the number of $\mathrm{F}$ increases, the angle increases. This is seen in Figure 16 with a good second-order polynomial correlation and one outlier (red) when the number of $\mathrm{F}$ is one.

If the bond angles are plotted in relation to the barrier heights there is no real trend to see. They appear to be scattered and the angle has no real impact on the barrier height (see Figure 17).

The last parameter that was looked at was the bond angle of the newly forming water molecule in the TS. There is an excellent linear correlation between the number of $\mathrm{F}$ and the average $\angle \mathrm{HOH}$ of the water molecule being formed, seen in Figure 18. It is almost completely linear except for one outlier 
TABLE 6: Number of F and their $\angle$ COC ranges of TS.

\begin{tabular}{lcc}
\hline Number of $F$ & COC $\left({ }^{\circ}\right)$ range $(\mathrm{TS})$ & Range magnitude \\
\hline 1 & $111.4-114.7$ & 3.3 \\
2 & $111.2-115.8$ & 4.6 \\
3 & $111.3-118.2$ & 6.9 \\
4 & $112.0-119.1$ & 7.1 \\
5 & $113.2-119.0$ & 5.8 \\
6 & $114.3-118.9$ & 4.6 \\
\hline
\end{tabular}

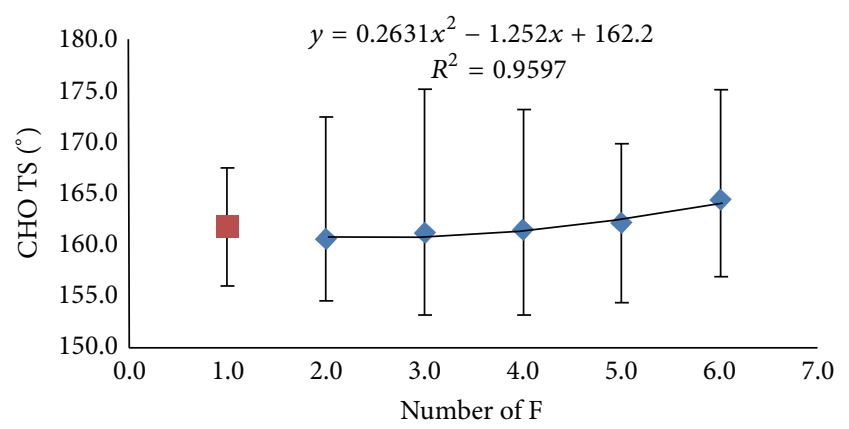

FIGURE 16: Average $\angle \mathrm{CHO}$ of TS versus the number of F.

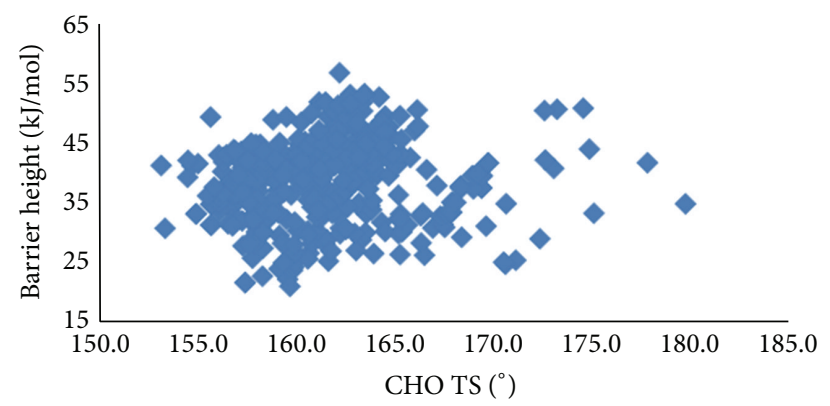

FIGURE 17: Barrier heights versus $\angle \mathrm{CHO}$ of the TS.

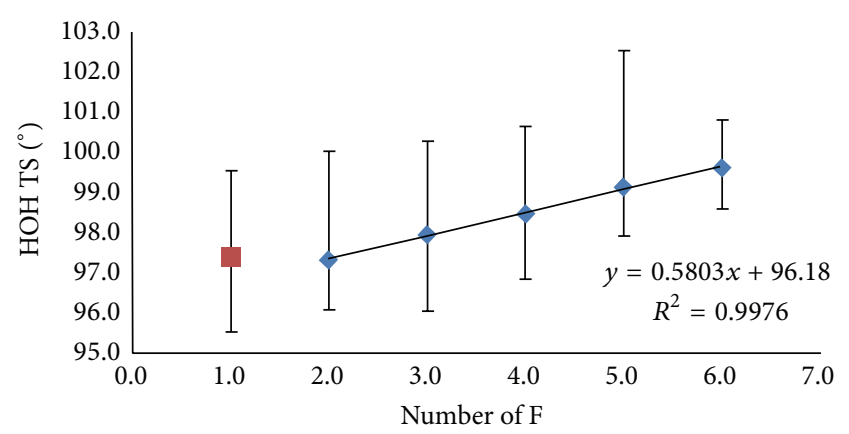

FIgURE 18: $\angle \mathrm{HOH}$ of the TS versus the number of $\mathrm{F}$.

(red) in the group with one $\mathrm{F}$, just like the $\angle \mathrm{CHO}$ relationship with F.

Also there is a clear linear trend in the data when the water angle and the barrier height are compared in that as the angle of water increases, the barrier height increases. This can be seen in Figure 19.

The next step was to look at how the bond angle of water in the TS differed from the bond angle of free water. The

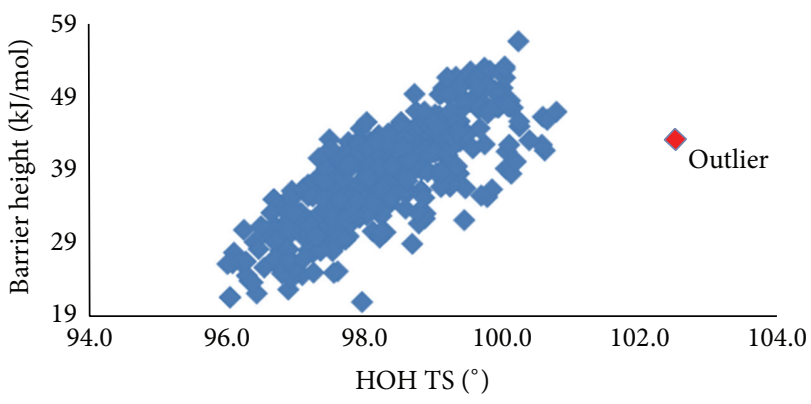

Figure 19: Barrier height versus $\angle \mathrm{HOH}$ in the TS.

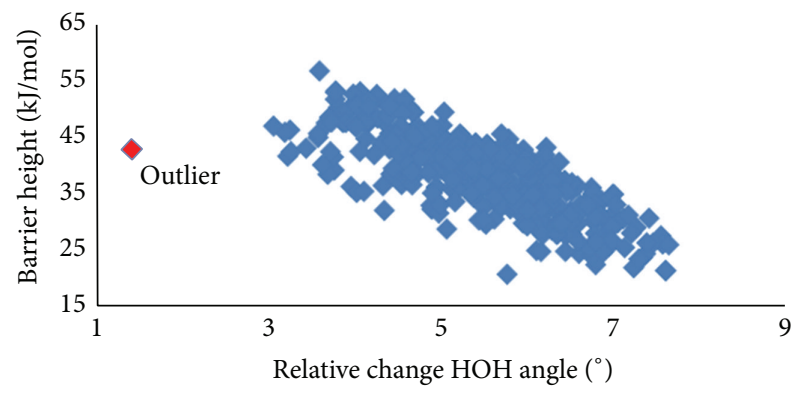

FIGURE 20: Barrier height versus relative change in $\angle \mathrm{HOH}$ between TS and free water bond angle.

hypothesis is that the more the bond angle must change, the more the energy must be placed into the reaction in order for it to proceed, but this is not what is seen. From Figure 20, it can be seen that the more the $\angle \mathrm{HOH}$ must change, the lower the barrier height is. Note that all the bond angles in the TS are less than that of free water $\left(104.5^{\circ}\right)$; therefore all bond angles must increase in order to reach this angle.

\section{Conclusions}

This study was started to evaluate the parameters of an EME that could possibly be used as an HFC. It would have to be an ether that when presented into the lower atmosphere would react with hydroxyl radicals and dissociate rather than moving higher and reacting with the ozone. In order to achieve this, the barrier height of the reaction with a hydroxyl radical abstracting hydrogen from the ether should be as low as possible. This is not the only condition for second generation HFCs; however, it must have the desired properties to act as a refrigerant, such as being a liquid at ambient conditions and having high thermal conductivity. Compounds being investigated for refrigerants are highly substituted with $\mathrm{F}$ and the results here show that the barrier heights increase with increasing substitution. However, even in these cases, barrier heights are relatively low. For example, the barrier height for $\mathrm{CF}_{3} \mathrm{CF}_{2} \mathrm{OCH}_{3}$ is only $41.7 \mathrm{~kJ} / \mathrm{mol}$.

It was found that this fluorinated ether would have to have a minimum of $\mathrm{F}$ attached to it since $\mathrm{F}$ raises the barrier height. The number of $\mathrm{F}$ also influences certain bond lengths. $\mathrm{C}-\mathrm{H}$ lengths in the reactants decrease with an increase in 
the number of $\mathrm{F}$, but $\mathrm{C}-\mathrm{H}$ lengths in the TS increase. $\mathrm{H}-$ $\mathrm{O}$ length is also decreased as the number of $\mathrm{F}$ is increased. Hydrogen bonding is influenced by the number of $\mathrm{F}$. When hydrogen bonding to oxygen is related to number of $\mathrm{F}$, a negative second-order polynomial correlation is found and when hydrogen bonding to $\mathrm{F}$ is related to number of $\mathrm{F}$, a positive second-order polynomial correlation is found.

It was also found that some factors can increase the barrier height of the hydrogen abstraction from an EME by a hydroxyl radical barrier height and some can decrease it. An increase in the number of $\mathrm{F}$ increases the barrier height of the reaction. Increased barrier heights are also seen with an increase in some parameters such as $\mathrm{C}-\mathrm{H}$ length of TS, relative change in $\mathrm{C}-\mathrm{H}$ from reactants to TS, $\angle \mathrm{COC}$ of reactants, $\angle \mathrm{HOH}$ in the TS, and relative change in $\angle \mathrm{HOH}$ between TS and free water bond angle. An increase in other parameters like $\mathrm{C}-\mathrm{H}$ of the reactants and hydrogen bonding can decrease the barrier height. As MP2/6-31G(p) geometries are well known to be accurate, and computed barrier heights with this method have a systematic error, we are confident that trends noted above are accurate within the correlations given.

\section{Conflict of Interests}

The authors declare that there is no conflict of interests regarding the publication of this paper.

\section{References}

[1] J. S. Francisco and M. M. Maricq, "Making sure that hydrofluorocarbons are 'ozone friendly", Accounts of Chemical Research, vol. 29, no. 8, pp. 391-397, 1996.

[2] F. Leroux, P. Jeschke, and M. Schlosser, " $\alpha$-Fluorinated ethers, thioethers, and amines: anomerically biased species," Chemical Reviews, vol. 105, no. 3, pp. 827-856, 2005.

[3] A. Sekiya and S. Misaki, "The potential of hydrofluoroethers to replace CFCs, HCFCs and PFCs," Journal of Fluorine Chemistry, vol. 101, no. 2, pp. 215-221, 2000.

[4] T. J. Wallington and O. J. Nielsen, "Atmospheric chemistry and environmental impact of hydrofluorocarbons (HFCs) and hydrofluoroethers (HFES)," in Organofluorines, vol. 3N, pp. 85102, Springer, Berlin, Germany, 2002.

[5] N. Oyaro, S. R. Sellevåg, and C. J. Nielsen, "Atmospheric chemistry of hydrofluoroethers: reaction of a series of hydrofluoroethers with $\mathrm{OH}$ radicals and $\mathrm{Cl}$ atoms, atmospheric lifetimes, and global warming potentials," The Journal of Physical Chemistry A, vol. 109, no. 2, pp. 337-346, 2005.

[6] L. Chen, S. Kutsuna, K. Tokuhashi, A. Sekiya, R. Tamai, and Y. Hibino, "Kinetics and mechanism of $\left(\mathrm{CF}_{3}\right)_{2} \mathrm{CHOCH}_{3}$ reaction with $\mathrm{OH}$ radicals in an environmental reaction chamber," The Journal of Physical Chemistry A, vol. 109, no. 21, pp. 4766-4771, 2005.

[7] E. W. Wilson Jr., W. A. Hamilton, and H. R. Mount, "Rate constants for the reactions of hydroxyl radical with several fluoroethers by the relative rate method," The Journal of Physical Chemistry A, vol. 111, no. 9, pp. 1610-1617, 2007.

[8] K.-J. Hsu and W. B. DeMore, "Temperature-dependent rate constants and substituent effects for the reactions of hydroxyl radicals with three partially fluorinated ethers," The Journal of Physical Chemistry, vol. 99, no. 28, pp. 11141-11146, 1995.

[9] N. L. Garland, L. J. Medhurst, and H. H. Nelson, "Potential chlorofluorocarbon replacements: $\mathrm{OH}$ reaction rate constants between 250 and $315 \mathrm{~K}$ and infrared absorption spectra," Journal of Geophysical Research, vol. 98, no. 12, pp. 23107-23111, 1993.

[10] K. Tokuhashi, A. Takahashi, M. Kaise et al., "Rate constants for the reactions of $\mathrm{OH}$ radicals with $\mathrm{CH}_{3} \mathrm{OCF}_{2} \mathrm{CHF}_{2}$, $\mathrm{CHF}_{2} \mathrm{OCH}_{2} \mathrm{CF}_{2} \mathrm{CHF}_{2}, \quad \mathrm{CHF}_{2} \mathrm{OCH}_{2} \mathrm{CF}_{2} \mathrm{CF}_{3}$, and $\mathrm{CF}_{3} \mathrm{CH}_{2} \mathrm{OCF}_{2} \mathrm{CHF}_{2}$ over the temperature range $250-430 \mathrm{~K}$," The Journal of Physical Chemistry A, vol. 104, no. 6, pp. 1165-1170, 2000.

[11] S. Urata, S. Tsuzuki, A. Takada, M. Mikami, T. Uchimaru, and A. Sekiya, "Analysis of the intermolecular interactions between $\mathrm{CH}_{3} \mathrm{OCH}_{3}, \mathrm{CF}_{3} \mathrm{OCH}_{3}, \mathrm{CF}_{3} \mathrm{OCF}_{3}$, and $\mathrm{CH}_{2} \mathrm{~F}_{2}, \mathrm{CHF}_{3}$," Journal of Computational Chemistry, vol. 25, no. 3, pp. 447-459, 2004.

[12] S. Urata, S. Tsuzuki, M. Mikami, A. Takada, T. Uchimaru, and A. Sekiya, "Analysis of the intermolecular interaction between $\mathrm{CH}_{3} \mathrm{OCH}_{3}, \mathrm{CF}_{3} \mathrm{OCH}_{3}, \mathrm{CF}_{3} \mathrm{OCF}_{3}$, and $\mathrm{CH}_{4}$ : high level ab initio calculations," Journal of Computational Chemistry, vol. 23, no. 15, pp. 1472-1479, 2002.

[13] S. Urata, T. Uchimaru, A. K. Chandra, A. Takada, and A. Sekiya, " $\mathrm{C}-\mathrm{H}$ bond dissociation enthalpies of fluorinated formates and estimation of their rate constants for the reactions with $\mathrm{OH}$ radicals: A DFT study," International Journal of Chemical Kinetics, vol. 34, no. 9, pp. 524-530, 2002.

[14] A. K. Chandra, S. Urata, T. Uchimaru, M. Sugie, and A. Sekiya, "Kinetics of hydrogen abstraction reaction between trifluoromethyl formate and $\mathrm{OH}$ radical: a theoretical investigation," International Journal of Chemical Kinetics, vol. 34, no. 8, pp. 500-507, 2002.

[15] D. A. Good and J. S. Francisco, "Bond dissociation energies and heats of formation for fluorinated ethers: E143A $\left(\mathrm{CH}_{3} \mathrm{OCF}_{3}\right)$, $\mathrm{E} 134\left(\mathrm{CHF}_{2} \mathrm{OCHF}_{2}\right)$, and $\mathrm{E} 125\left(\mathrm{CF}_{3} \mathrm{OCHF}_{2}\right)$," The Journal of Physical Chemistry A, vol. 102, no. 36, pp. 7143-7148, 1998.

[16] P. Blowers, K. F. Tetrault, and Y. Trujillo-Morehead, "Global warming potential predictions for hydrofluoroethers with two carbon atoms," Theoretical Chemistry Accounts, vol. 119, no. 4, pp. 369-381, 2008.

[17] A. M. El-Nahas, T. Uchimaru, M. Sugie, K. Tokuhashi, and A. Sekiya, "Hydrogen abstraction from dimethyl ether (DME) and dimethyl sulfide (DMS) by OH radical: a computational study," Journal of Molecular Structure, vol. 722, no. 1-3, pp. 9-19, 2005.

[18] G. Johnson, C. A. Gonzales, P. M. W. Gill, and J. A. Pople, "A density functional study of the simplest hydrogen abstraction reaction. Effect of self-interaction correction," Chemical Physics Letters, vol. 221, no. 1-2, pp. 100-108, 1994.

[19] P. M. W. Gill, R. D. Adamson, and J. A. Pople, "Coulombattenuated exchange energy density functionals," Molecular Physics, vol. 88, no. 4, pp. 1005-1009, 1996.

[20] D. R. B. Brittain, C. Y. Lin, A. T. B. Gilbert, E. I. Izgorodina, P. M. W. Gill, and M. L. Coote, "The role of exchange in systematic DFT errors for some organic reactions," Physical Chemistry Chemical Physics, vol. 11, no. 8, pp. 1138-1142, 2009.

[21] M. J. Frisch, G. W. Trucks, H. B. Schlegel et al., “Gaussian 03," D. 01; Gaussian Inc, 2003.

[22] J. M. Martell, Z. Shi, and R. J. J. Boyd, "Effects of electron correlation on the series C2HnF6- $\mathrm{n}(\mathrm{n}=0-6)$ : geometries, total energies, and C-C and C-H bond dissociation energies," The Journal of Physical Chemistry A, vol. 97, no. 28, pp. 7208$7215,1993$. 
[23] J. M. Martell, A. K. Mehta, P. D. Pacey, and R. J. Boyd, "Properties of transition species in the reaction of hydroxyl with ethane from ab initio calculations and fits to experimental data," Journal of Physical Chemistry, vol. 99, no. 21, pp. 8661-8668, 1995.

[24] J. M. Martell and R. J. Boyd, "Ab initio studies of reactions of hydroxyl radicals with fluorinated ethanes," The Journal of Physical Chemistry, vol. 99, no. 36, pp. 13402-13411, 1995.

[25] V. Guner, K. S. Khuong, A. G. Leach, P. S. Lee, M. D. Bartberger, and K. N. Houk, "A standard set of pericyclic reactions of hydrocarbons for the benchmarking of computational methods: the performance of ab initio, density functional, CASSCF, CASPT2, and CBS-QB3 methods for the prediction of activation barriers, reaction energetics, and transition state geometries," The Journal of Physical Chemistry A, vol. 107, no. 51, pp. 11445-11459, 2003.

[26] L. A. Curtiss, K. Raghavachari, G. W. Trucks, and J. A. Pople, "Gaussian-2 theory for molecular energies of first-and secondrow compounds," The Journal of Chemical Physics, vol. 94, no. 11, pp. 7221-7230, 1991.

[27] L. A. Curtiss, K. Raghavach Ari, P. C. Redfern, V. Rassolov, and J. A. Pople, "Gaussian-3 (G3) theory for molecules containing first and second-row atoms," Journal of Chemical Physics, vol. 109, no. 18, pp. 7764-7776, 1998.

[28] L. A. Curtiss, P. C. Redfern, K. Raghavachari, V. Rassolov, and J. A. Pople, "Gaussian-3 theory using reduced Møller-Plesset order," The Journal of Chemical Physics, vol. 110, no. 10, pp. 47034709, 1999.

[29] D. H. Ess and K. N. Houk, "Activation energies of pericyclic reactions: performance of DFT, MP2, and CBS-QB3 methods for the prediction of activation barriers and reaction energetics of 1,3-dipolar cycloadditions, and revised activation enthalpies for a standard set of hydrocarbon pericyclic reactions," The Journal of Physical Chemistry A, vol. 109, no. 42, pp. 9542-9535, 2005. 

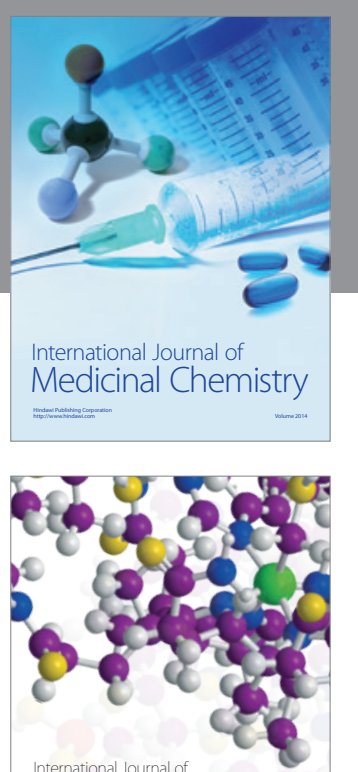

Carbohydrate Chemistry

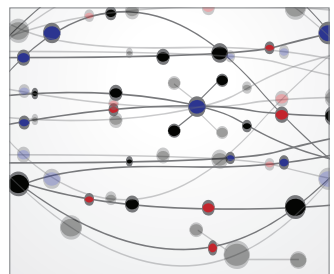

The Scientific World Journal
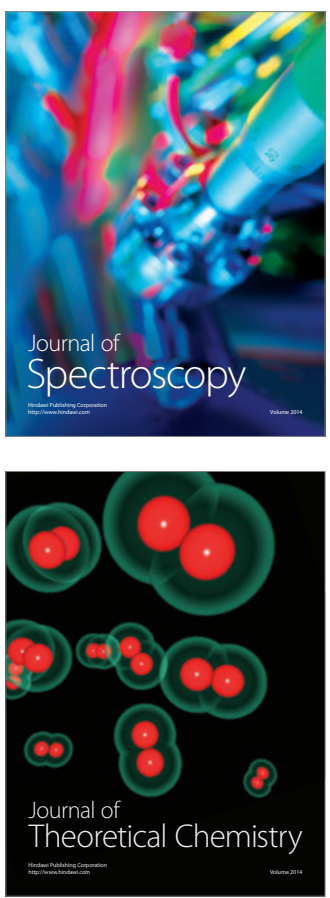
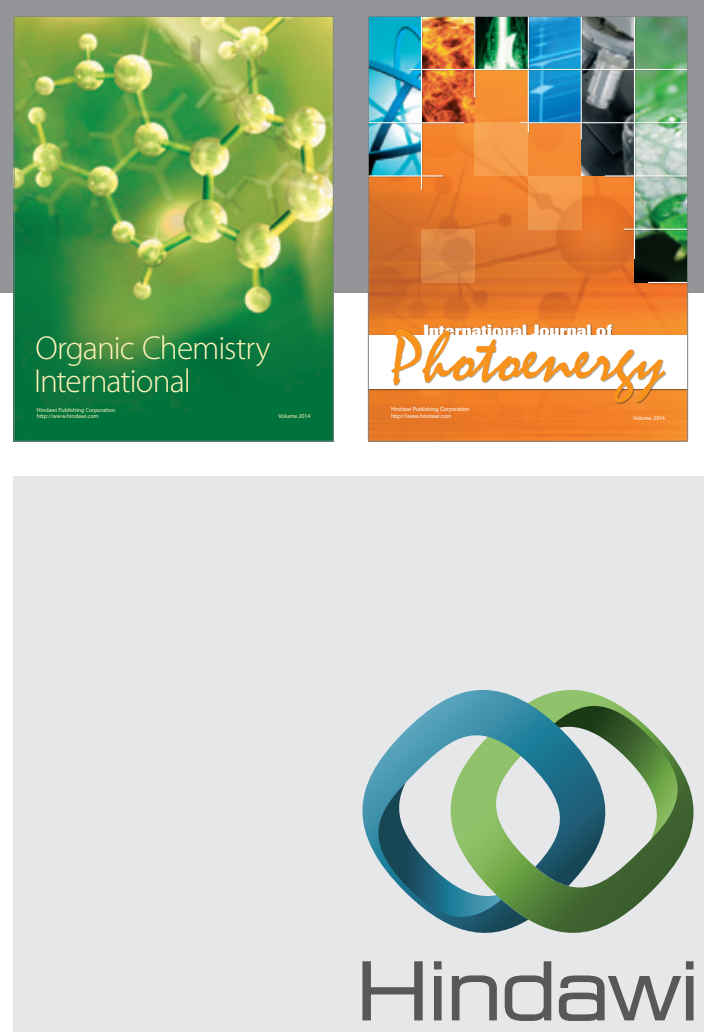

Submit your manuscripts at

http://www.hindawi.com

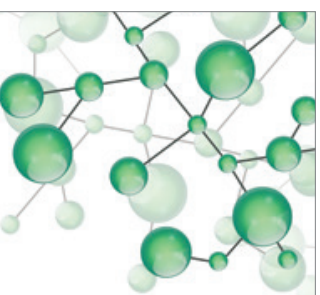

International Journal of

Inorganic Chemistry

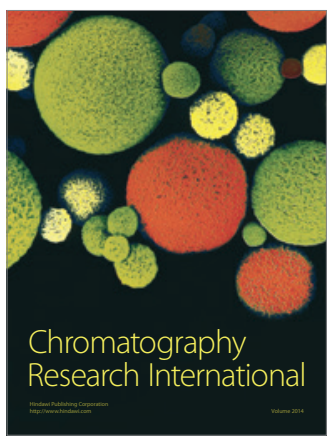

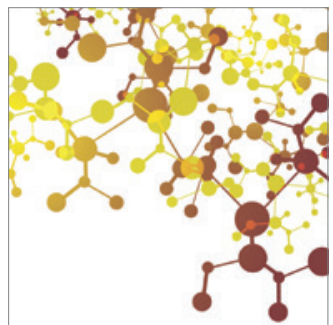

Applied Chemistry
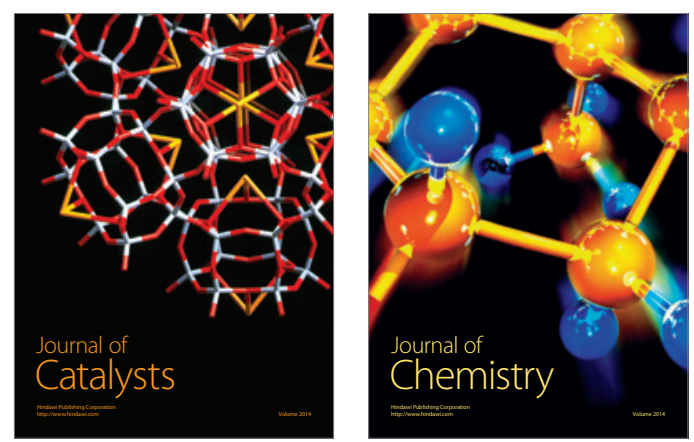
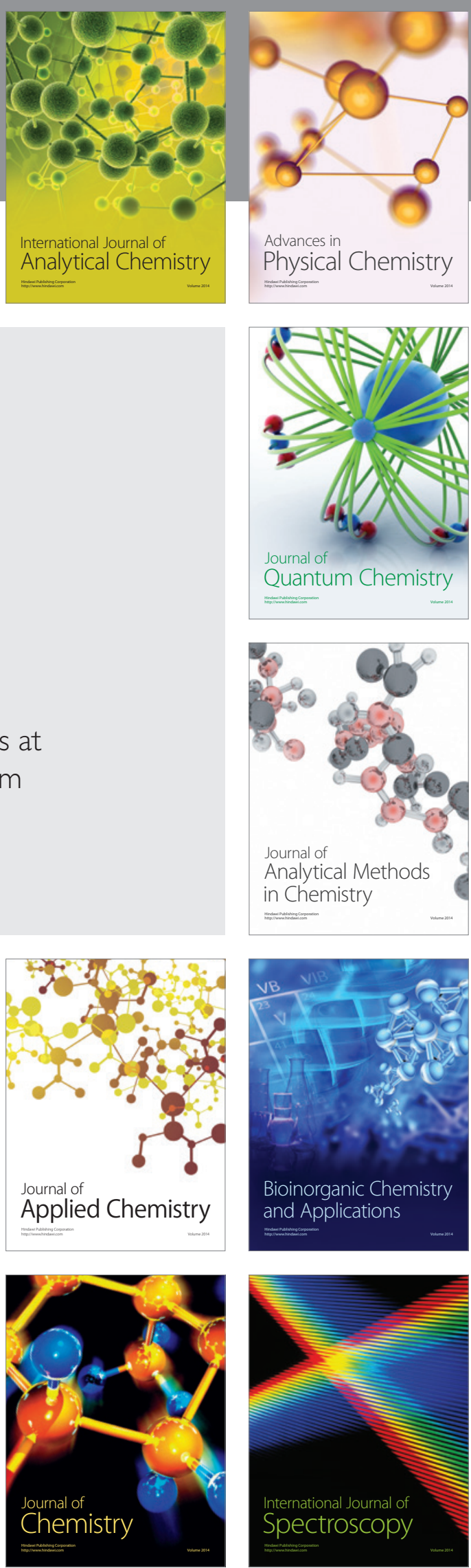